\title{
Factors for a successful citizen science on the example of bumblebee observations on naturbeobachtung.at
}

\section{Gernot Neuwirth ${ }^{\mathbf{1}}$}

Naturschutzbund Österreich, Salzburg, Austria

E-mail: gernot.neuwirthenaturschutzbund.at

\section{Johann Neumayer}

Naturschutzbund Österreich, Salzburg, Austria

E-mail: johann. neumayerenaturschutzbund.at

\section{Walter Wallner}

Naturschutzbund Österreich, Salzburg, Austria

E-mail: w. wall nerlsbg.at

The bumblebee focus of the online platform naturbeobachtung.at has developed into a high quality zoogeographic data source and a place of collecting observation data from citizens, bringing them in contact with zoogeographic and ecological questions and connecting them to a network of common interests and shared competences.

The main factors for the success are a sophisticated technology, prompt support for Citizen Scientists via internet and a long-term community building by public courses, common mapping excursions and presentations. Long term-engagement in know-how-transfer and support guarantees high quality data and an increasing community, that raises public awareness of the value of pollinators and the pollinator crisis. 


\section{Introduction}

In recent years, abundances of bee species have continued to decline. In some areas of Central Europe pollination is no longer a free ecological service. In contrast to honeybees, there is a lack of data concerning the distribution of wild bee species, including bumblebees (Bombus $s p$.). They are important pollinators of many wild and cultivated plants. Since 2014 citizens report observations on naturbeobachtung.at in order to gain data of the occurrence and distribution of bumblebee species in Austria [1]. The verified data provide a profound basis for further scientific work and nature conservation projects. This project is in line with many other citizen science projects in Europe investigating trends in pollinator occurrences [2], [3]. Opposite to some other projects [4], [5], validation of all data was fundamental for naturbeobachtung.at.

\section{Material and Methods}

In 2006 the online platform www.naturbeobachtung.at has been established by the Naturschutzbund Österreich. The platform was designed for reporting a large number of various species. The list of reportable species on the platform has constantly been expanded. Since 2014 all Central European bumblebees are part of them.

The procedure of bumblebee registrations is easy for beginners with an expanding option for advanced users. Mandatory fields to fill out in reports are species name (including "unknown", which will be determined later by experts), date, and coordinates of the visited location. Additionally also details as caste, weather conditions or plants visited can be reported via a specific reporting mask, allowing experts to investigate phenological or flower ecology issues.

Experts verify or correct all determinations and identify specimens which have not been recognized by the reporting persons. In periods of high activity, reports are checked daily. A traffic light system ensures a double check of all reports. After verification, the user receives a notification with the result of the identification.

In order to obtain high quality data, users can pick different sources of information before uploading a bumblebee observation to the database - e.g. reading fact sheets about bumblebee species or directly ask bumblebee experts in the integrated forum to get help during the identification.

A step-by-step system enables newcomers to upgrade their qualification. Over time, they carry out more and more tasks - from simply reporting bumblebees, to helping in the discussion forum, until assisting in species determination.

Since 2018, bumblebees can also be reported via the associated app "naturbeobachtung.at", an application for Android and iOS. The app shows a much simpler report form and includes a mandatory image upload. The app also allows the upload of image series (more than one photo upload per observation), which facilitates the time-consuming validation tasks of the experts. Another new feature of the app is the possibility to comment directly on the reported bumblebee observation. This "less formal" communication (compared to the discussion forum) reduces the time needed by experts to validate an observation. 


\section{Results and Discussion}

By the end of 2019, Citizen Scientists have reported more than 31,200 bumblebee observations on naturbeobachtung.at. While in 2014, 25 different bumblebee species had been documented, this number increased to 42 in 2019, meaning that all 42 bumblebee species currently occurring in Austria got reported by citizens. There is a steady increase in reports (Fig. 1).

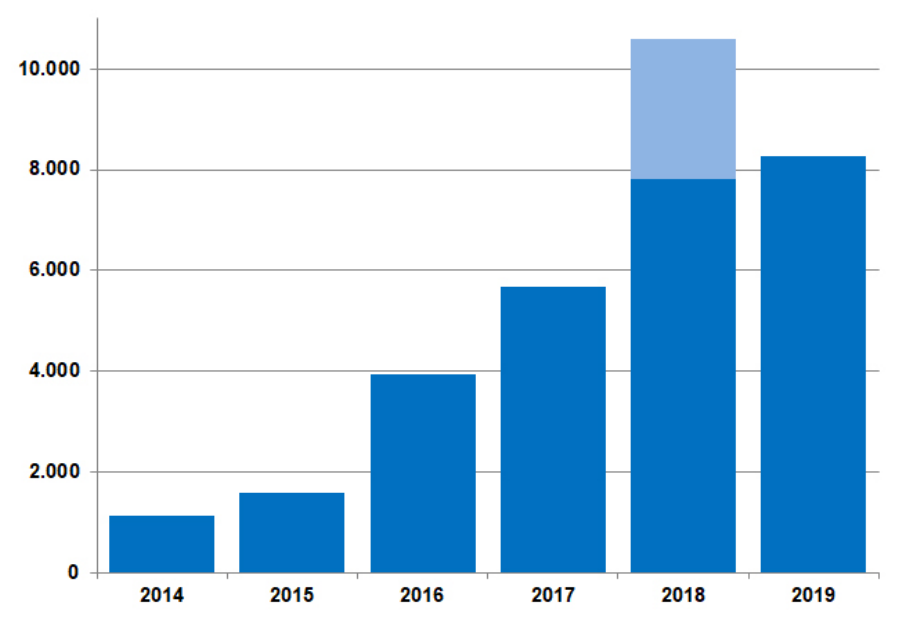

Fig. 1: The number of bumblebee reports from 2014 to 2019 on naturbeobachtung.at. The maximum in 2018 is caused by a campaign with Austrian schools (light blue).

The current rate of more than 8,000 validated reports per year represents around seven percent of all bumblebee data collected in Austria. This adds up to the five- to eightfold amount of data gathered by scientific projects and arbitrary observations.

For many rare species, including the extremely rare Bombus pomorum, Bombus veteranus, Bombus confusus and Bombus muscorum, the reports on naturbeobachtung.at are either the only observations or make up for the major part of reports from the last 30 years. Among these species is the "unexpected bumblebee" Bombus inexspectatus that was found in the southern part of Carinthia in 2019 (Fig. 2). Since its first description in 1963 it has been reported just a few times in Austria.

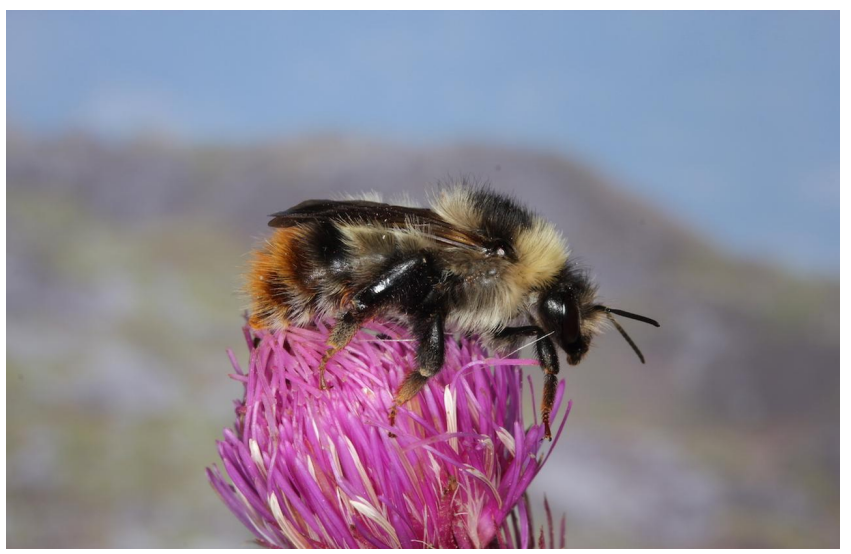

Fig. 2: The "unexpected bumblebee" - Bombus inexpectatus - was seen in Austria on 16.08.2019 in 9640 KötschachMauthen/Carinthia. It got reported and verified on naturbeobachtung.at. (c) Martin Streinzer 
Besides that, the project also showed surprising phenological data, e.g. very early nesting cycles of the montane Bombus jonellus in Hochzirl in Tyrol at $>1,000 \mathrm{~m}$ NN (queen on on 27th of February 2017, first male on 8th of April 2017) and in Kraubath in Styria (several males on 24th of April 2017). In times of climate warming the large amounts of Citizen Science data are a valuable phenological data source. Within the scope of the project also interesting data series of newly immigrating species such as Bombus haematurus were received.

The photographs additionally provide interesting information about the habitats and the interactions of the species. The documentation of food plants e.g. showed, which bumblebee species uses which plants as pollen sources and when.

Some observations by Citizen Scientists consequently led to excursions for estimating population sizes of rare species. These data provide a good basis for monitoring the populations of species that suffered heavy declines in the last decades and helps to observe further changes as well as the effect of restoration measures.

The bumblebee distribution data collected on naturbeobachtung.at will be included in a distribution atlas and a red data book of Austrian bumblebees.

\section{Conclusions and Implications}

The Citizen Science project on the basis of www.naturbeobachtung.at gathered widespread data of bumblebee species in Austria with remarkable results. The cooperation between bumblebee experts, citizens, and technicians enables the creation of an extensive and high quality database. Technical and media professionalism (data quality, acquisition and support of detectors) can only be guaranteed with appropriate financial means. Fortunately, a company sponsor was found. Under these conditions, Citizen Science is a promising instrument for obtaining high quality data for bumblebees.

Another reason for the success is the sophisticated and well tested online platform. The volunteer work in Citizen Science is very important, too, and should not be overstretched. A system-based online validation tool and other technical features were found to be convenient resources to increase user-friendliness for participants. The involvement of "amateur experts" as support in the discussion forum and in assisting in the determination work also proved to be effective.

\section{References}

[1] Neumayer J, Pachinger B, Schneller B Bosser S. (2016): Addressing bumblebee faunistic and ecology using Citizen Science - reviewing a 2-year experience. Austrian Citizen Science Conference 2016. Frontiers in Environmental Science: 27-30.

[2] O'Connor RS, Kunin WE, Garratt MPD, Potts, SG, Roy HE et al, (2019): Monitoring insect pollinators and flower visitation: The effectiveness and feasibility of different survey methods. Methods Ecol Evol 10 (12): 2129-2140.

[3] Cima, V, Fontaine B, Witté I, Dupont M, Touroult J (2020): A test of six simple indices to display the phenology of butterflies using a large multi-source database. Ecol Indic 110: 105831.

[4] Roy HE, Baxter E, Saunders A, Pocock MJO (2016): Focal Plant Observations as a standardised Method for Pollinator Monitoring: Opportunities and Limitations for Mass 
Factors for a successful citizen science on the example of bumblebee observations on naturbeobachtung.at Gernot Neuwirth, Johann Neumayer, Walter Wallner

Participation Citizen Pcience. PLoS ONE 11(3):

e0150794.doi:10.1371/journal.pone.0150794

[5] Falk S, Foster G, Comont R, Conroy J,Bostock H, Salisbury A, et al. (2019): Evaluating the ability of citizen scientists to identify bumblebee (Bombus) species. PLoSONE 14(6): e0218614. https://doi.org/10.1371/journal.pone.

\section{Acknowledgement}

Our special thanks are extended to the bumblebee-community on naturbeobachtung.at and all the dedicated citizens who made the great success possible. We also would like to express our very great appreciation to Norbert Hirneisen from science4you for approaching the application naturbeobachtung.at and we thank Martina Winkler helping with the formulation of the text. 